\title{
Stability of gene expression and epigenetic profiles highlights the utility of patient-derived paediatric acute lymphoblastic leukaemia xenografts for investigating molecular mechanisms of drug resistance
}

Nicholas C Wong ${ }^{1,2,4+}$, Vivek A Bhadri ${ }^{3+}$, Jovana Maksimovic ${ }^{1}$, Mandy Parkinson-Bates ${ }^{1}$, Jane $\mathrm{Ng}^{1}$, Jeff M Craig ${ }^{1,4}$, Richard Saffery ${ }^{1,4 \dagger}$ and Richard B Lock ${ }^{3 * \dagger}$

\begin{abstract}
Background: Patient-derived tumour xenografts are an attractive model for preclinical testing of anti-cancer drugs. Insights into tumour biology and biomarkers predictive of responses to chemotherapeutic drugs can also be gained from investigating xenograft models. As a first step towards examining the equivalence of epigenetic profiles between xenografts and primary tumours in paediatric leukaemia, we performed genome-scale DNA methylation and gene expression profiling on a panel of 10 paediatric B-cell precursor acute lymphoblastic leukaemia (BCP-ALL) tumours that were stratified by prednisolone response.

Results: We found high correlations in DNA methylation and gene expression profiles between matching primary and xenograft tumour samples with Pearson's correlation coefficients ranging between 0.85 and 0.98 . In order to demonstrate the potential utility of epigenetic analyses in BCP-ALL xenografts, we identified DNA methylation biomarkers that correlated with prednisolone responsiveness of the original tumour samples. Differential methylation of CAPS2, ARHGAP21, ARX and HOXB6 were confirmed by locus specific analysis. We identified 20 genes showing an inverse relationship between DNA methylation and gene expression in association with prednisolone response. Pathway analysis of these genes implicated apoptosis, cell signalling and cell structure networks in prednisolone responsiveness.
\end{abstract}

Conclusions: The findings of this study confirm the stability of epigenetic and gene expression profiles of paediatric BCP-ALL propagated in mouse xenograft models. Further, our preliminary investigation of prednisolone sensitivity highlights the utility of mouse xenograft models for preclinical development of novel drug regimens with parallel investigation of underlying gene expression and epigenetic responses associated with novel drug responses.

Keywords: Acute lymphoblastic leukaemia, Xenografts, Genome-wide DNA methylation, Microarray analysis of gene expression, Glucocorticoid resistance

\footnotetext{
*Correspondence: rlock@ccia.unsw.edu.au

${ }^{\dagger}$ Equal contributors

${ }^{3}$ Children's Cancer Institute Australia for Medical Research, Lowy Cancer

Research Centre, UNSW, PO Box 81, Sydney, NSW 2052, Australia

Full list of author information is available at the end of the article
} 


\section{Background}

Despite progress in the treatment of several cancers over recent decades, the lack of clinically relevant tumour models for individual subtypes of human cancer has proven to be a major impediment in the development of effective anti-cancer therapies [1]. Approaches that facilitate development of novel rational therapies targeting specific tumours (or specific features of tumours) remain an urgent priority. Traditional models of human cancer involving the analysis of immortalised cell lines have given way in recent years to more clinically relevant studies in models that mirror the features of primary tumours [2]. The two main approaches have been the generation of primary tumour-derived cell lines, and the generation of mouse models, either via transgenic approaches or through the engraftment of primary human tumour into immune-compromised mouse models [3]. Mouse models have been used extensively in this regard, for preclinical testing of drug efficacy and toxicity prior to establishing clinical trials. A broad panel of xenografts with known treatment responsiveness, and well-defined molecular profiles, would provide an excellent adjunct to these models [4].

Mouse xenograft models of haematological malignancies, established by the transplantation of donor cells into non-obese diabetic/severe combined immunodeficient (NOD/SCID) or NOD/SCID/IL-2 receptor gamma chain $^{-1-}$ (NSG) mice, are recognised as one of the most clinically relevant systems for investigating leukaemia biology and testing new treatments [5-12]. This is due to the faithful recapitulation of many aspects of the human disease, including kinetics of engraftment in the bone marrow (BM), with subsequent infiltration of the spleen, peripheral blood and other organs [10,13,14]. For these reasons, patient-derived xenografts (PDXs) are considered superior to in vitro immortalised cancer cell lines that show many differences to primary tumours, including gene expression, drug responsiveness and epigenetic profiles [15], which is most likely due to the selective processes associated with long term culturing. PDXs have become increasingly popular as evidence mounts that they accurately recapitulate many of the features of patient tumours, such as tumour microenvironment, differentiation state and morphology, architecture and in some instances molecular signatures of the original patient tumour (reviewed in [1,2]).

To establish the relevance of PDX models to primary tumours, high density molecular profiling of gene expression and epigenetic markers should be performed. This was recently demonstrated for gene expression both between two tissue types, bone marrow and spleen and between independently engrafted mice for T-ALL [16].

As a first step towards examining the equivalence of epigenetic profiles between primary tumour and xenograft, we carried out parallel DNA methylation and gene expression profiling on a panel of childhood B-cell precursor acute lymphoblastic leukaemia (BCP-ALL) selected by their clinical responses to prednisolone. This panel consisted of five individuals who had a good response to prednisolone (PGR) and five who had a poor response (PPR). By comparing DNA methylation and gene expression profiles between primary and derived, singlepassaged xenograft lines, we report the stability of both gene expression and DNA methylation in the xenograft, further highlighting their potential for exploring gene expression and epigenetic changes associated with responses to established and novel drugs.

\section{Methods}

\section{Patient samples, characteristics and xenograft model generation}

All experimental studies were approved by the Human Research Ethics Committee and the Animal Care and Ethics Committee of the University of New South Wales. Written informed consent was obtained from the parents or guardians of paediatric ALL patients for use of biopsy samples in research, with the exception of samples obtained prior to May 2003 (ALL-26, ALL-28 and ALL-53), for which a waiver had been issued by the Human Research Ethics Committee. A total of 10 xenograft lines were generated from children diagnosed with BCP-ALL. Individuals were selected based on their response to prednisolone. We classified prednisolone poor responders (PPR) as patients with a peripheral blast count of $\geq 1 \times 10^{9} / \mathrm{L}$ on day 8 following induction treatment with prednisolone and a single intrathecal dose of methotrexate, while a prednisolone good responder (PGR) demonstrated a day 8 peripheral blast count of $<1 \times 10^{9} / \mathrm{L}$ (Table 1 ). Xenografts were established in NOD/SCID or NSG mice using direct explants of patient BM biopsies, exactly as described previously $[10,17]$. When mice were highly engrafted with leukaemia human $\mathrm{CD} 45^{+}$, mononuclear cells were isolated from spleens by FACS at $>90 \%$ purity and cryopreserved for subsequent experiments.

\section{Genomic DNA and total RNA extraction}

Genomic DNA was extracted from the primary bone marrow biopsies used for xenografting and from cells harvested from the spleens of engrafted animals for each xenograft using standard phenol/chloroform extraction and isopropanol precipitation. Total RNA was extracted using TriZol Reagent (Life Technologies, Carlsbad, USA) according to manufacturer's instructions. Quality and yield were measured using a Nanodrop spectrophotometer.

\section{Sodium bisulphite conversion of genomic DNA}

Genomic DNA was converted for DNA methylation analysis using the MethylEasy Xceed Kit (Human Genetic 
Table 1 Patient demographics of xenografts used in this study

\begin{tabular}{|c|c|c|c|c|c|c|c|c|}
\hline & Xenograft & Sex & $\begin{array}{c}\text { Age } \\
\text { (Months) }\end{array}$ & Cytogenetics & $\begin{array}{c}\text { Immunophenotype } \\
\text { (Diagnostic patient sample) }\end{array}$ & $\begin{array}{c}\text { Diagnosis WCC } \\
\times 10^{9} / \mathrm{L}\end{array}$ & $\begin{array}{c}\text { Diagnosis blasts } \\
\times 10^{9} / \mathrm{L}\end{array}$ & $\begin{array}{l}\text { Day } 8 \text { blasts } \\
\times 10^{9} / \mathrm{L}\end{array}$ \\
\hline PPR & ALL-28 & M & 20 & Hyperdiploid & CD45-/DR+/10+/19+/2-/7-/13-/33+/34+ & 15.0 & 11.8 & 1.9 \\
\hline PPR & ALL-50 & M & 131 & Normal & CD45+/DR+/10+/19+/20+ & 34.6 & 26.1 & 5.5 \\
\hline PPR & ALL-54 & M & 89 & Normal & $\mathrm{CD} 45+/ \mathrm{DR}+/ 10+/ 19+/ 20+/ 34+/ 13-/ 33-$ & 185.0 & 174.8 & 1.2 \\
\hline PPR & ALL-55 & M & 176 & $\mathrm{t}(9 ; 22)$ & CD45+/DR+/10+/19+/13+/33+/34+ & 422.5 & 388.7 & 22.6 \\
\hline PPR & ALL-57 & $\mathrm{F}$ & 72 & $t(1 ; 19)$ & CD45+/DR+/19+/10+/34-2-/7- & 15.9 & 7.2 & 1.6 \\
\hline PGR & ALL-26 & $\mathrm{F}$ & 43 & $t(12 ; 21)$ & CD45+/DR+/CD19+/10+/22+/3-/34+/117-/Cu-/TdT+ & 89.4 & 80.5 & 0.0 \\
\hline PGR & ALL-51 & M & 19 & $\operatorname{dic}(7 ; 9)$ & CD45+/DR+/CD19+/10+/22+/34-/117-/Cu-/TdT+ & 90.5 & 76.9 & 0.0 \\
\hline PGR & ALL-52 & M & 138 & $t(7 ; 15)$ & $\mathrm{CD} 45+/ \mathrm{DR}+/ \mathrm{CD} 19+/ 22+/ 13+/ 33+/ 10-/ 34-/ \mathrm{Cu}-/ \mathrm{TdT}+$ & 14.4 & 4.0 & 0.0 \\
\hline PGR & ALL-53 & M & 87 & $t(12 ; 21)$ & CD45+/DR+/10+/19+/34+ & 20.3 & 13.8 & 0.1 \\
\hline PGR & ALL-56 & M & 120 & $\mathrm{t}(9 ; 22)$ & CD45-/DR+/10+/19+/34+/2-/7-/13-/33- & 8.5 & 0.1 & 0.0 \\
\hline
\end{tabular}


Signatures, Sydney, Australia) according to manufacturer's instructions. Converted DNA was used for downstream Illumina Infinium DNA methylation BeadArray analysis and SEQUENOM EpitTYPER validation.

\section{Genome-scale DNA methylation analysis}

Converted genomic DNA was processed and analysed for Illumina Infinium HumanMethylation27 BeadArray (Illumina, San Diego, USA) according to manufacturer's instructions (ServiceXS, Leiden, The Netherlands). This BeadArray platform interrogates 27,578 CpG sites across the human genome. The arrays were scanned using an Illumina BeadArray Reader and subsequently processed using the Illumina GenomeStudio V.1 software package. The Bioconductor Lumi package was used for downstream data processing and normalisation [18]. Briefly, DNA probe methylation data were quality checked and then colour balance adjusted, background corrected and scaled based on the mean of all probes, using the methylation simple scaling normalization (SSN) implemented within the Lumi package. CpG sites with at least one sample having a detection $\mathrm{p}$-value $>0.01$ were excluded from subsequent analyses, leaving 27,341 CpG sites. Differential methylation analysis was performed using the LIMMA package from Bioconductor [19]. Significantly differentially methylated probes were selected based on a Benjamini-Hochberg adjusted $\mathrm{p}$-value $<0.05$. The methylation microarray data have been deposited into Gene Expression Ominibus (http://www.ncbi.nlm.nih.gov/geo/) with the identifier GSE57581.

\section{Gene expression Illumina array analysis}

Total RNA was extracted from the primary and xenograft tumours and amplified using the Illumina TotalPrep RNA amplification kit (Ambion, Austin, USA). The amplified total RNA was analysed using Illumina WG-6_V3 chips (Illumina, San Diego, USA) according to manufacturer's instructions. The sample probe profiles with no normalisation or background correction were exported from BeadStudio (version 3.0.14, Illumina), and the data were pre-processed using quantile normalisation. Probes with detection p-value greater than 0.01 on all arrays were deemed as nonexpressed probes and filtered out. Differential gene expression was determined using LIMMA with the positive False Discovery Rate (FDR) correction for multiple testing (Benjamini-Hochberg adjusted p-value $<0.05$ ). The gene expression microarray data have been deposited into Gene Expression Ominibus (http://www.ncbi.nlm.nih.gov/ geo/) with the identifier GSE57491.

\section{SEQUENOM MassArray EpiTYPER analysis}

Primers (detailed in Additional file 1: Table S1) were designed to generate PCR amplicons from bisulphite converted genomic DNA suitable for SEQUENOM
EpiTYPER chemistry as per the manufacturer's protocol. Samples were analysed using MALDI-TOF mass spectrometry, DNA methylation information was collected using EpiTYPER Viewer Software (v 1.0.5). Non-analysable and poor quality $\mathrm{CpG}$ sites were removed from downstream analysis as previously described [20].

\section{Results}

Xenograft models of BCP-ALL are an accurate reflection of DNA methylation and gene expression status of the corresponding primary tumour

One sample in our analysis, ALL28P, failed to meet array quality metrics (low overall signal intensity). Therefore, the matching xenograft pair, ALL28X along with ALL28P gene expression data was removed from subsequent analysis. ALL28 was also removed from the DNA methylation and gene expression correlation analysis herein

Plotting the beta values of the entire data set revealed similar DNA methylation profiles between primary tumour tissue and the matching xenograft from each of the 10 patients in our study. Similarly, gene expression levels between primary tumour tissue and xenograft were also comparable (Figure 1A). For genome-scale DNA methylation, Pearson's correlation coefficients between matching primary and xenograft samples ranged between 0.94-0.98 while correlation coefficients between individuals ranged between 0.80-0.91. For genome-wide gene expression, Pearson's correlation coefficients between primary and xenograft samples ranged between 0.85-0.97 and between individuals was greater than 0.83-0.96 (Figure 1B). Gene expression profiles between individuals were more correlated than their DNA methylation profiles.

Consistent with this observation, unsupervised hierarchical clustering of the most variable DNA methylation and gene expression across all samples revealed clustering of matching primary and xenograft samples. This implies that the profiles from the xenografts recapitulate the profile of the primary tumour (Figure $1 \mathrm{C}$ ).

To identify differential DNA methylation between primary tumour and matching xenograft samples we applied a linear model with empirical Bayes estimation and found 1564 probes to be differentially methylated between matching primary tumour and xenograft sample after correction for multiple testing (adjusted p-value < 0.05 , Additional file 2: Table S2). The majority of these probes demonstrated a small change in DNA methylation with the average difference across individuals ranging from 0.4 to $8.6 \%$ (Additional file 3: Figure S1A).

We also looked for differential gene expression between matching primary and xenograft cell lines again applying a linear model with empirical Bayes estimation on the genome-scale gene expression microarray results. We found 3441 probes from 3208 genes to be differentially expressed between primary and xenograft lines 


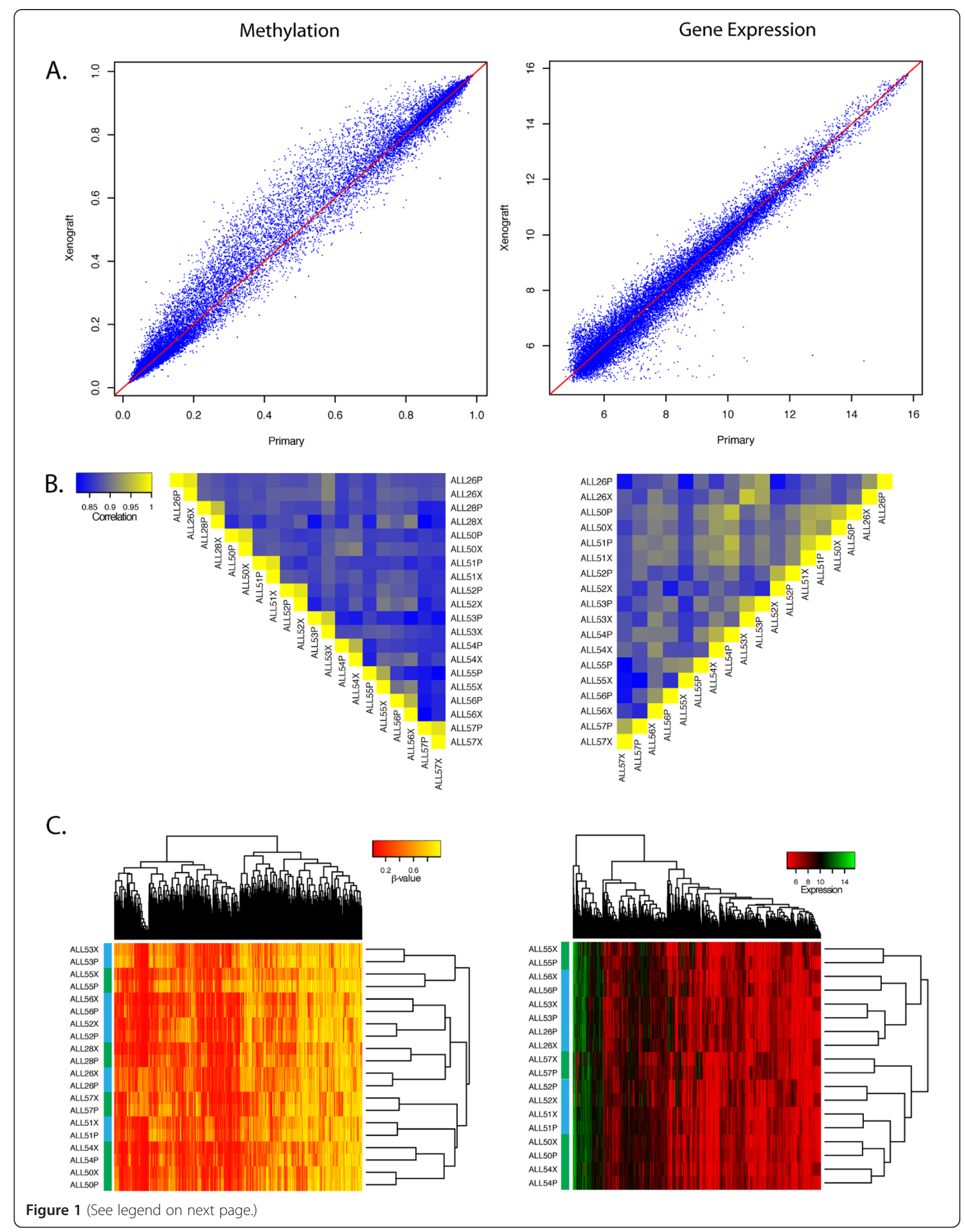


(See figure on previous page.)

Figure 1 Comparisons of DNA methylation and gene expression profiles between primary tumour tissue and xenografts. (A) Scatterplots of DNA methylation and gene expression array results from ALL26 showing high correlation between primary and xenograft tumours. (B) Heatmap plot of Pearson's correlation coefficients of all primary and xenograft samples analysed for DNA methylation and gene expression. Coefficients greater than 0.94 and 0.84 between matching primary and xenograft tumours were observed for DNA methylation and gene expression respectively. (C) Heatmap plot of the most variable DNA methylation and gene expression probes. A high level of similarity between matching primary and xenograft tumours resulted in all pairs clustering together. Green Sample Bar depicts PPR, Blue sample Bar depicts PGR.

(adjusted p-value $<0.05$, Additional file 4: Table S3). However, as we observed with DNA methylation, the differences in expression of these probes between primary and xenograft were minimal with an average fold difference in expression between primary and xenograft tumours of 1.12 (Additional file 3: Figure S1B).

Using DAVID (http://david.abcc.ncifcrf.gov/), the differentially methylated and differentially expressed genes between primary and matching xenograft lines were found to be mainly involved in haematological and cell signalling processes that could be accounted for given the cellular origins of the primary (bone marrow) and xenograft (spleen) samples.

Given the relatively small number of differentially methylated probes (6\%) and differentially expressed probes (17\%), and the minimal absolute differences in DNA methylation and expression (Additional file 3: Figure S1A and S1B), our results indicate that xenograft models largely recapitulate the DNA methylation and gene expression profile of the corresponding primary tumour. This highlights the potential utility of xenograft cell lines for modelling primary disease.

\section{Molecular biomarkers associated with prednisolone response}

We then sought to identify differential DNA methylation and gene expression associated with prednisolone poor (PPR) and prednisolone good (PGR) responders and included primary and xenograft samples in our analysis. After correction for multiple testing, 35 DNA methylation probes were differentially methylated between PPR and PGR (Benjamini-Hochberg adjusted p-value $<0.05$, Table 2, Figure 2). Gene expression analysis revealed 23 genes differentially expressed between PPR and PGR (Benjamini-Hochberg adjusted $\mathrm{p}$-value $<0.05$, Table 2, Figure 2). From these lists, we did not find any commonly annotated genes associated with prednisolone response between the top differentially methylated and top differentially expressed probes. Differential DNA methylation segregated PPR from PGR by supervised hierarchical clustering and may serve as potential biomarkers for prednisolone response (Figure 2A). However, interrogating gene expression alone did not accurately segregate PPR from PGR (Figure 2B). Functional annotation of differentially methylated genes annotated to these probes identified a number of apoptotic, cell signalling/structure pathways that did not reach statistical significance (Additional file 5: Table S4).

We then determined the relationship between DNA methylation and gene expression in association with prednisolone response. Plotting the average DNA methylation and gene expression differences between PPR and PGR revealed 22 probes annotated to 12 genes that were more highly expressed and less methylated in PPR samples compared to PGR samples (gene expression cut-off greater than 2 and a DNA methylation cut-off of less than -0.2 , Figure 3 , Table 3). Conversely, 11 probes annotated to 8 genes were less highly expressed and more methylated in PPR samples compared to PPR (gene expression cut-off of less than -2 and a DNA methylation cut-off greater than 0.2, Figure 3, Table 3). With the exception of expression probes annotated to PAWR, MTX2 and MYO3A no other gene expression and DNA methylation probes reached statistical significance (Table 3 ). DNA methylation probes associated with PAWR, MTX2 and MYO3A demonstrated an average difference of $>0.2$ between groups but did not reach significance with LIMMA analysis between PPR and PGR.

\section{Validation of DNA methylation biomarkers associated with prednisolone response}

From our array analysis, the DNA methylation changes segregated samples by prednisolone response. We validated 17 of these probes using SEQUENOM EpiTYPER chemistry on both primary and xenograft samples by selecting from our LIMMA analysis, those also associated with changes in gene expression (Additional file 6: Figure S2). Of the assays containing the 17 probes of interest, 4 regions continued to discriminate samples according to prednisolone response (Figure 4). These were associated with the genes CAPS2 and ARHGAP21 (less methylated in PPR), $A R X$ and HOXB6 (more methylated in PPR). Primary and matching xenograft samples showed similar DNA methylation levels in all cases.

\section{Discussion}

It is becoming clear that the complexity of genetic, epigenetic, and subsequent gene expression disruption associated with human cancer is immense. As such, many mouse models of tumourigenesis are limited in their 
Table 2 Differential probes associated with prednisolone response

\begin{tabular}{|c|c|c|c|c|c|}
\hline Probe type & Probe ID & Gene symbol & $\begin{array}{l}\text { Adjusted } \\
\text { p-value }\end{array}$ & ACC & DESC \\
\hline \multirow[t]{35}{*}{$\begin{array}{l}\text { DNA } \\
\text { methylation } \\
\text { probes }\end{array}$} & cg02780988 & KRTHA6 & 0.0001 & NM_003771 & keratin 36 \\
\hline & $\operatorname{cg} 16848873$ & HOXB6 & 0.0001 & NM_018952 & homeobox B6 \\
\hline & cg00546897 & LOC284837 & 0.0002 & NM_194310 & \\
\hline & cg02789485 & MGC39497 & 0.0007 & NM_152436 & GLI pathogenesis-related 1 like 2 \\
\hline & cg01605783 & LOC284837 & 0.0010 & NM_194310 & \\
\hline & cg20291222 & CAPS2 & 0.0012 & NM_032606 & calcyphosine 2 \\
\hline & cg05724065 & PHKG1 & 0.0019 & NM_006213 & phosphorylase kinase, gamma 1 (muscle) \\
\hline & $\operatorname{cg} 00645579$ & IRF7 & 0.0033 & NM_001572 & interferon regulatory factor 7 \\
\hline & $\operatorname{cg} 02100629$ & AMID & 0.0158 & NM_032797 & apoptosis-inducing factor, mitochondrion-associated, 2 \\
\hline & cg20649991 & LILRB5 & 0.0170 & NM_006840 & $\begin{array}{l}\text { leukocyte immunoglobulin-like receptor, subfamily B (with } \\
\text { TM and ITIM domains), } \\
\text { member } 5\end{array}$ \\
\hline & cg11952714 & SNX7 & 0.0170 & NM_015976 & sorting nexin 7 \\
\hline & cg20050826 & K6IRS2 & 0.0170 & NM_080747 & keratin 72 \\
\hline & cg21306775 & FLJ44881 & 0.0190 & NM_207461 & \\
\hline & cg20468883 & BNIP2 & 0.0202 & NM_004330 & BCL2/adenovirus E1B 19kDa interacting protein 2 \\
\hline & cg08739282 & $\mathrm{DHX15}$ & 0.0202 & NM_001358 & DEAH (Asp-Glu-Ala-His) box polypeptide 15 \\
\hline & cg03172991 & NFIX & 0.0211 & NM_002501 & nuclear factor I/X (CCAAT-binding transcription factor) \\
\hline & $\operatorname{cg} 19238840$ & GP2 & 0.0211 & NM_001007240 & glycoprotein 2 (zymogen granule membrane) \\
\hline & $\operatorname{cg} 10148841$ & $\mathrm{ROBO} 4$ & 0.0223 & NM_019055 & roundabout homolog 4, magic roundabout (Drosophila) \\
\hline & cg09892390 & ARHGAP21 & 0.0254 & NM_020824 & Rho GTPase activating protein 21 \\
\hline & cg05961212 & ADPRH & 0.0254 & NM_001125 & ADP-ribosylarginine hydrolase \\
\hline & $\operatorname{cg} 22844623$ & GJA12 & 0.0254 & NM_020435 & gap junction protein, gamma $2,47 \mathrm{kDa}$ \\
\hline & cg18096388 & PDCD1 & 0.0255 & NM_005018 & programmed cell death 1 \\
\hline & cg05921324 & APOA4 & 0.0255 & NM_000482 & apolipoprotein A-IV \\
\hline & $\operatorname{cg} 13633560$ & LRRC32 & 0.0270 & NM_005512 & leucine rich repeat containing 32 \\
\hline & $\operatorname{cg} 19573166$ & SLC22A17 & 0.0270 & NM_020372 & solute carrier family 22, member 17 \\
\hline & $\operatorname{cg} 01410472$ & CRISPLD1 & 0.0277 & NM_031461 & cysteine-rich secretory protein LCCL domain containing 1 \\
\hline & $\operatorname{cg} 26624914$ & AQP3 & 0.0377 & NM_004925 & aquaporin 3 (Gill blood group) \\
\hline & cg23752985 & VAMP8 & 0.0389 & NM_003761 & vesicle-associated membrane protein 8 (endobrevin) \\
\hline & cg21148892 & CLEC4F & 0.0389 & NM_173535 & C-type lectin domain family 4 , member $F$ \\
\hline & cg00032666 & CXorf6 & 0.0402 & NM_005491 & mastermind-like domain containing 1 \\
\hline & $\operatorname{cg} 19511844$ & ORMDL3 & 0.0418 & NM_139280 & ORM1-like 3 (S. cerevisiae) \\
\hline & $\operatorname{cg} 16127900$ & GPRC6A & 0.0466 & NM_148963 & G protein-coupled receptor, family C, group 6, member A \\
\hline & $\operatorname{cg} 12552392$ & NFS1 & 0.0475 & NM_181679 & \\
\hline & $\operatorname{cg} 22437699$ & ARX & 0.0479 & NM_139058 & aristaless related homeobox \\
\hline & cg02849695 & CCDC19 & 0.0486 & NM_012337 & coiled-coil domain containing 19 \\
\hline \multirow[t]{4}{*}{$\begin{array}{l}\text { Gene expression } \\
\text { probes }\end{array}$} & ILMN_1806907 & PAWR & 0.0000 & NM_002583 & PRKC, apoptosis, WT1, regulator \\
\hline & ILMN_1794046 & MTX2 & 0.0119 & $\begin{array}{l}\text { NM_006554 } \\
\text { NM_001006635 }\end{array}$ & Metaxin 2 \\
\hline & ILMN_1758128 & CYGB & 0.0119 & NM_134268 & Cytoglobin \\
\hline & ILMN_1738438 & MAST4 & 0.0157 & NM_198828 & $\begin{array}{l}\text { Microtubule associated serine/threonine kinase family } \\
\text { member } 4\end{array}$ \\
\hline
\end{tabular}


Table 2 Differential probes associated with prednisolone response (Continued)

\begin{tabular}{|c|c|c|c|c|}
\hline ILMN_1789384 & QSOX2 & 0.0190 & NM_181701 & Quiescin Q6 sulfhydryl oxidase 2 \\
\hline ILMN_2306565 & MTX2 & 0.0190 & $\begin{array}{l}\text { NM_006554 } \\
\text { NM_001006635 }\end{array}$ & Metaxin 2 \\
\hline ILMN_2295987 & NBPF1 & 0.0237 & NM_017940 & Neuroblastoma breakpoint family, member 1 \\
\hline ILMN_1765772 & MYO3A & 0.0305 & NM_017433 & Myosin IIIA \\
\hline ILMN_1713934 & LITAF & 0.0305 & NM_004862 & Lipopolysaccharide-induced TNF factor \\
\hline ILMN_1668125 & MYRIP & 0.0305 & NM_015460 & Myosin VIIA and Rab interacting protein \\
\hline ILMN_1681888 & PRKAR2A & 0.0305 & NM_004157 & Protein kinase, cAMP-dependent, regulatory, type II, alpha \\
\hline ILMN_2184966 & $\mathrm{ZHX} 2$ & 0.0305 & NM_014943 & Zinc fingers and homeoboxes 2 \\
\hline ILMN_1706505 & COL5A1 & 0.0305 & NM_000093 & Collagen, type V, alpha 1 \\
\hline ILMN_1656057 & PLAU & 0.0305 & NM_002658 & Plasminogen activator, urokinase \\
\hline ILMN_1761540 & SEMA3F & 0.0305 & NM_004186 & $\begin{array}{l}\text { Sema domain, immunoglobulin domain }(\mathrm{lg}) \text {, short basic } \\
\text { domain, secreted, (semaphorin) 3F }\end{array}$ \\
\hline ILMN_1753143 & DKFZp761L1918 & 0.0305 & NM_033103 & Homo sapiens rhophilin-like protein mRNA, complete cds. \\
\hline ILMN_2148944 & $\mathrm{ADCY} 4$ & 0.0305 & NM_139247 & Adenylate cyclase 4 \\
\hline ILMN_1812618 & ARAP3 & 0.0305 & NM_022481 & ArfGAP with RhoGAP domain, ankyrin repeat and PH domain 3 \\
\hline ILMN_1681081 & AGPAT2 & 0.0359 & NM_006412 & $\begin{array}{l}\text { 1-acylglycerol-3-phosphate O-acyltransferase } 2 \text { (lysophospha- } \\
\text { tidic acid acyltransferase, beta) }\end{array}$ \\
\hline ILMN_1743275 & SH3RF3 & 0.0359 & NM_001099289 & $\mathrm{SH} 3$ domain containing ring finger 3 \\
\hline ILMN_1656951 & APCDD1 & 0.0359 & NM_153000 & Adenomatosis polyposis coli down-regulated 1 \\
\hline ILMN_1719756 & ZAP70 & 0.0359 & $\begin{array}{l}\text { NM_207519 } \\
\text { NM_001079 }\end{array}$ & Zeta-chain (TCR) associated protein kinase $70 \mathrm{kDa}$ \\
\hline ILMN_1768732 & SPAG16 & 0.0437 & $\begin{array}{l}\text { NM_024532 } \\
\text { NM_001025436 }\end{array}$ & Sperm associated antigen 16 \\
\hline
\end{tabular}

capacity to faithfully mimic human disease. In light of this, patient derived tumour tissue xenograft models are increasingly recognised as offering the most robust approach for testing tumour responses to various chemotherapeutic regimens, evaluating the efficacy of novel therapeutic agents, analysing the process of tumour progression at the cellular and molecular level and the identification of new therapeutic targets [2]. However, as with most mouse xenograft models, the stability of molecular profiles (gene expression and epigenetic) that regulate all aspects of
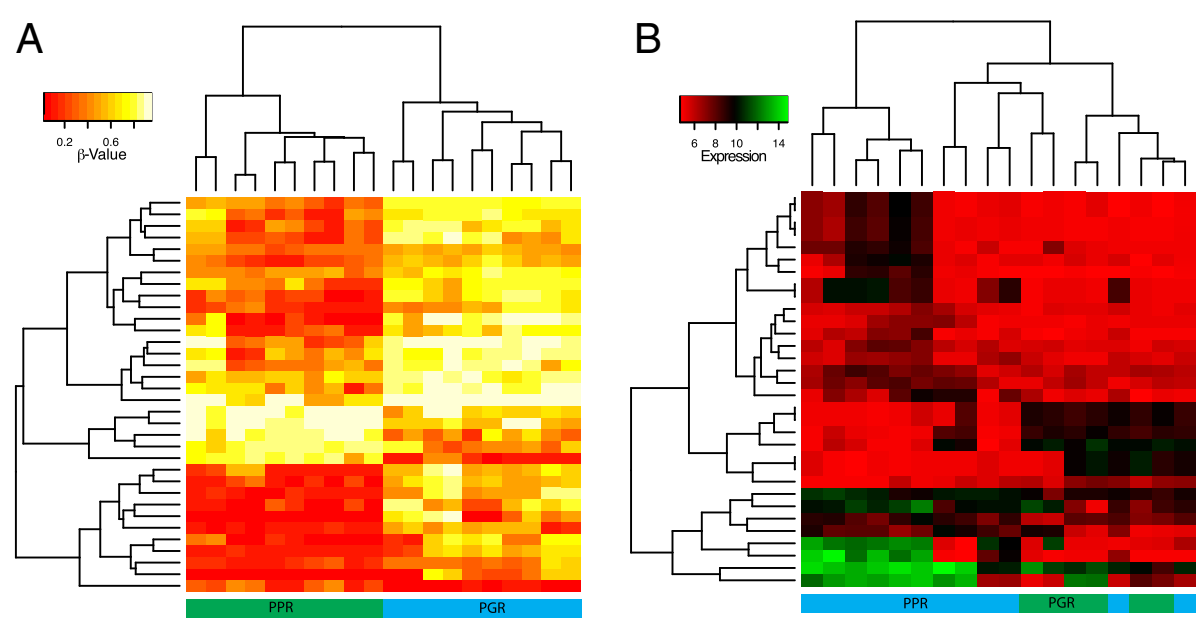

Figure 2 Heatmap plot of the most significant DNA methylation and gene expression probes distinguishing prednisolone good responders (PGR) from poor responders (PPR) after LIMMA analysis (BH adjusted $p$-value $<0.05)$. DNA methylation probes distinguished PGR from PPR while gene expression probes did not. 


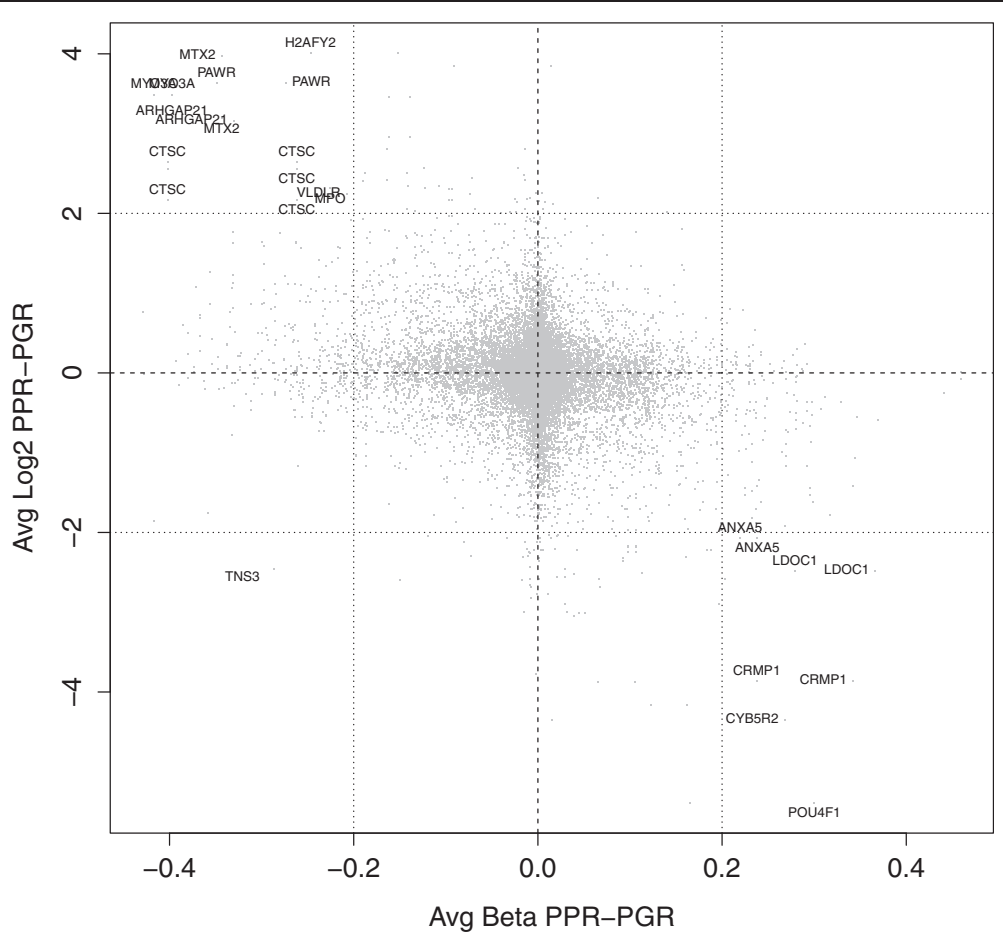

Figure 3 Scatterplot of the average DNA methylation and gene expression difference between PPR and PGR samples reveals 20 genes with a negative association between gene expression and DNA methylation.

tumour function remains to be determined. Confirmation of this stability is crucial in order identify molecular responses to treatment within the xenograft that could be extrapolated back to patients.

Here, we have determined the stability of genome wide DNA methylation and gene expression profiles between primary tumour cells and matching xenograft tumour cells from a small number of paediatric ALL cases with differential response to prednisolone. A high correlation in both DNA methylation and gene expression profiles was observed in all cases, confirming the stability of these molecular features of primary tumours in the mouse system. Differences in DNA methylation and gene expression between primary and xenograft samples were negligible in magnitude (Additional file 3: Figure S1) and comprised of a small fraction of probes for each array platform. The differentially methylated genes include MYOD1, GPR6 and SLC27A6 (Table 1). Many genes associated with minor expression differences were part of the globin gene family and genes involved in oxygen transport and include $H B B$, AHSP, $H B D, H B A 2$ (Table 2). This is likely to have arisen by the differences in cellular composition as the primary tumour samples contained a milieu of haematopoietic cells, including human erythrocytes that were absent in the xenograft samples that comprised of mononuclear cells derived from the murine spleen. Given the high degree of correlation and clustering of matching primary and xenograft samples after unsupervised hierarchical clustering of the most varied probes for DNA methylation and gene expression, the xenografts described in this study are an accurate reflection of their corresponding primary tumours.

While a number of candidate genes whose DNA methylation and/or gene expression status were associated with prednisolone response, given the small sample numbers and inherent genetic heterogeneity of the tumours, the significance of these genes remains unclear. Using hierarchical clustering, the most significant probes for DNA methylation discriminated prednisolone response while the gene expression probes did not (Figure 2), reflecting the more variable nature of gene expression compared to DNA methylation [21,22]. Using SEQUENOM, we were able to replicate DNA methylation changes at four genes associated with prednisolone response indicative of a potential DNA methylation biomarker. Taking methylation and expression status together, 20 genes were differentially regulated between good and poor responders to prednisolone (Table 3). While the genes were found to be part of apoptotic and cell signalling pathways, their significance remains unclear given the small numbers in each group. PAWR demonstrated significant overexpression and hypomethylation across PPRs compared to PGRs. This is a WT1 interacting protein that also functions as a transcriptional repressor with pro-apoptotic functions and tumour resistance [23]. While the down regulation of $P A W R$ confers poor prognosis in a range 
Table 3 Probes both differentially methylated and expressed in association with prednisolone response

\begin{tabular}{|c|c|c|c|c|c|c|}
\hline Threshold & Gene_symbol.x & Gene_description.x & $\begin{array}{l}\text { Expression } \\
\text { adj.P.Val }\end{array}$ & $\begin{array}{c}\text { Methylation } \\
\text { adj.P.Val }\end{array}$ & methDiff & expDiff \\
\hline $\begin{array}{l}\text { Upregulated and less methylated } \\
\text { in PPR }\end{array}$ & H2AFY2 & $\mathrm{H} 2 \mathrm{~A}$ histone family, member $\mathrm{Y} 2$ & 0.1173 & 0.1782 & -0.2204 & 4.0116 \\
\hline \multirow[t]{21}{*}{$\begin{array}{l}\text { ( }>2 \text {-fold expression, }<-0.2 \\
\text { methylation) }\end{array}$} & $\mathrm{H} 2 \mathrm{AFY} 2$ & H2A histone family, member $\mathrm{Y} 2$ & 0.1173 & 0.3973 & -0.3007 & 4.0116 \\
\hline & MTX2 & Metaxin 2 & 0.0190 & 0.3673 & -0.4061 & 3.9695 \\
\hline & PAWR & PRKC, apoptosis, WT1, regulator & 0.0000 & 0.3154 & -0.4185 & 3.6350 \\
\hline & PAWR & PRKC, apoptosis, WT1, regulator & 0.0000 & 0.3973 & -0.3026 & 3.6350 \\
\hline & MYO3A & Myosin IIIA & 0.0305 & 0.2944 & -0.4156 & 3.4893 \\
\hline & MYO3A & Myosin IIIA & 0.0305 & 0.3154 & -0.4006 & 3.4893 \\
\hline & MTX2 & Metaxin 2 & 0.0119 & 0.3673 & -0.4061 & 3.1908 \\
\hline & BX537570 & & 0.2492 & 0.0333 & -0.3571 & 3.1574 \\
\hline & BX537570 & & 0.2492 & 0.1707 & -0.4761 & 3.1574 \\
\hline & CTSC & Cathepsin C & 0.0624 & 0.1782 & -0.4239 & 2.6472 \\
\hline & CTSC & Cathepsin C & 0.0624 & 0.2267 & -0.2834 & 2.6472 \\
\hline & CTSC & Cathepsin C & 0.0766 & 0.1782 & -0.2834 & 2.5574 \\
\hline & CTSC & Cathepsin C & 0.0766 & 0.2267 & -0.4239 & 2.5574 \\
\hline & MOSC1 & $\begin{array}{l}\text { MOCO sulphurase C-terminal domain } \\
\text { containing } 1\end{array}$ & 0.0578 & 0.5189 & -0.2051 & 2.5035 \\
\hline & NGFRAP1 & $\begin{array}{l}\text { Nerve growth factor receptor } \\
\text { (TNFRSF16) associated protein } 1\end{array}$ & 0.4360 & 0.4775 & -0.2504 & 2.4066 \\
\hline & MARCKS & $\begin{array}{l}\text { Myristoylated alanine-rich protein } \\
\text { kinase C substrate }\end{array}$ & 0.5467 & 0.4154 & -0.2603 & 2.3418 \\
\hline & MPO & Myeloperoxidase & 0.5920 & 0.4097 & -0.2226 & 2.3130 \\
\hline & CTSC & Cathepsin C & 0.0578 & 0.1782 & -0.2834 & 2.1699 \\
\hline & CTSC & Cathepsin C & 0.0578 & 0.2267 & -0.4239 & 2.1699 \\
\hline & CCR7 & Chemokine (C-C motif) receptor 7 & 0.2918 & 0.4434 & -0.2264 & 2.0570 \\
\hline & PLS3 & Plastin 3 (T isoform) & 0.6662 & 0.3610 & -0.2919 & 2.0256 \\
\hline $\begin{array}{l}\text { Downregulated and more } \\
\text { methylated in PPR }\end{array}$ & POU4F1 & POU class 4 homeobox 1 & 0.1004 & 0.4404 & 0.3017 & -5.3928 \\
\hline \multirow[t]{10}{*}{$\begin{array}{l}\text { (<-2-fold expression, }>0.2 \\
\text { methylation) }\end{array}$} & CYB5R2 & Cytochrome b5 reductase 2 & 0.1734 & 0.5066 & 0.2699 & -4.3486 \\
\hline & TMED6 & $\begin{array}{l}\text { Transmembrane emp24 protein } \\
\text { transport domain containing } 6\end{array}$ & 0.0504 & 0.5271 & 0.2317 & -4.1584 \\
\hline & CRMP1 & Collapsin response mediator protein 1 & 0.3007 & 0.4431 & 0.3668 & -3.8640 \\
\hline & CRMP1 & Collapsin response mediator protein 1 & 0.3007 & 0.3996 & 0.2607 & -3.8640 \\
\hline & $\mathrm{IRX} 3$ & Iroquois homeobox 3 & 0.5401 & 0.4957 & 0.2710 & -2.9003 \\
\hline & LDOC1 & $\begin{array}{l}\text { Leucine zipper, down-regulated } \\
\text { in cancer } 1\end{array}$ & 0.2608 & 0.6055 & 0.2578 & -2.4859 \\
\hline & DSC3 & Desmocollin 3 & 0.5401 & 0.4585 & 0.3377 & -2.2248 \\
\hline & DSC3 & Desmocollin 3 & 0.5401 & 0.4402 & 0.3561 & -2.2248 \\
\hline & ANXA5 & Annexin A5 & 0.5923 & 0.3699 & 0.2228 & -2.0708 \\
\hline & ANXA5 & Annexin A5 & 0.5923 & 0.3727 & 0.2386 & -2.0708 \\
\hline
\end{tabular}

of solid tumours [24,25], its role in haematological malignancy is less clear, with expression detectable in a range of leukaemias [26]. Our results warrant further investigation of $P A W R$ to determine a potential role in prednisolone response and responses to other novel drug regimens in an expanded xenograft cohort.

Another gene with potential interest is POU4F1, which appears to be differentially regulated according 

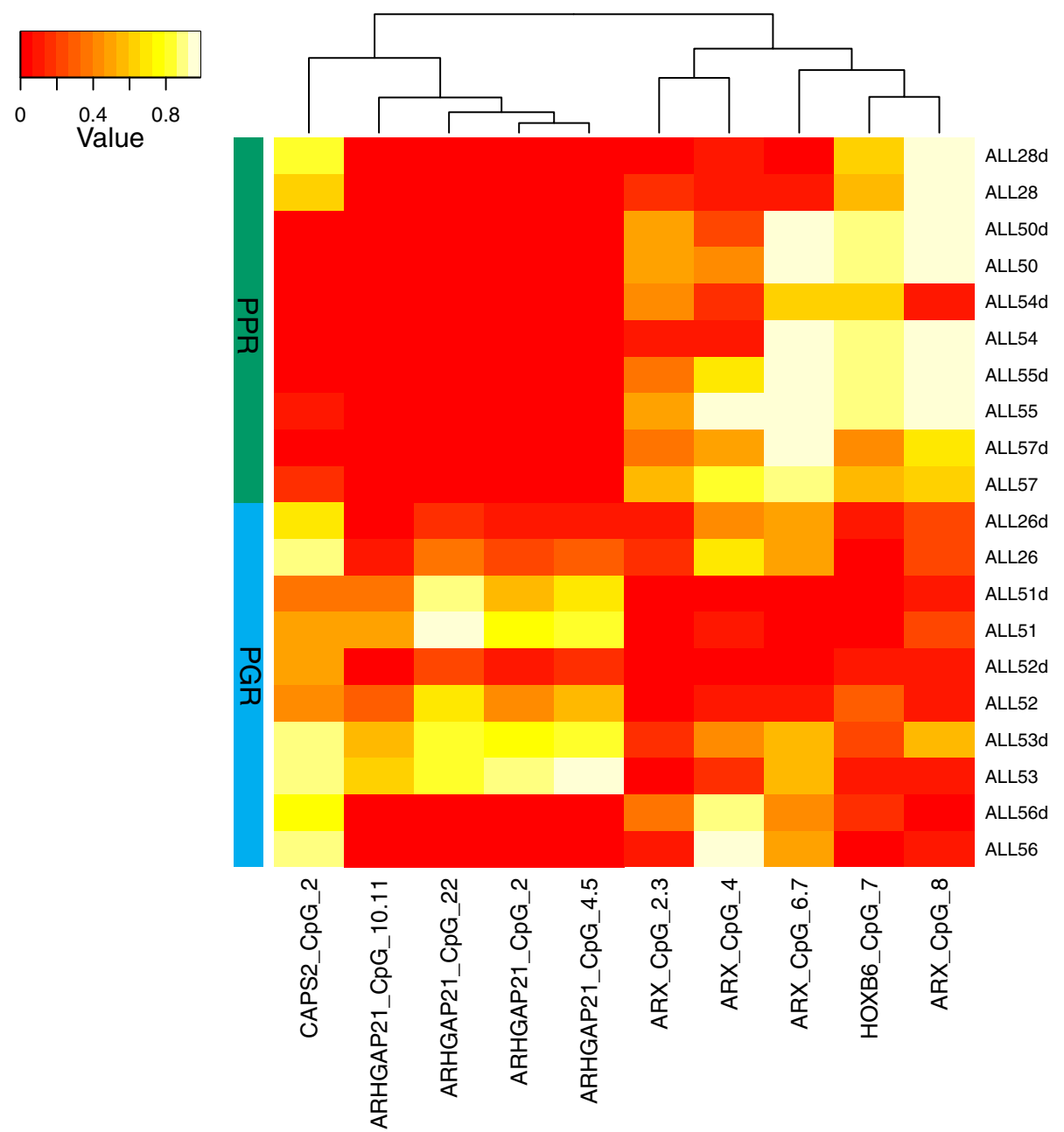

Figure 4 Validation of DNA methylation across four probes, CAPS2, ARHGAP21, ARX and HOXB6 using SEQUENOM EpiTYPER chemistry.

to prednisolone response (Table 3). However in our analysis, statistical significance was not achieved with the modest sample size of our panel. POU4F1 has been shown to have a role in regulating the expression of $\mathrm{B}$-cell markers in $\mathrm{t}(8 ; 21)$ positive acute myeloid leukaemia [27-29]. Its role in B-cell ALL response to prednisolone remains unclear and could be a potential gene target for further characterisation in an expanded B-cell ALL xenograft panel.

While our study did not identify statistically significant genes associated with prednisolone response, we present here a first pass analysis using low-resolution microarray platforms to interrogate DNA methylation and gene expression across our model system. We demonstrate that our B-cell ALL xenograft panel recapitulates the DNA methylation and gene expression profiles of the primary tumour and will facilitate future genome-wide interrogation of gene expression and DNA methylation using next generation sequencing methodology.

\section{Conclusions}

Patient-derived tumour xenograft models offer superior utility as preclinical models over cell line systems with their ability to recapitulate the milieu and microenvironment of the primary tumour. However, the extent of gene expression and epigenetic stability within the xenograft has remained unclear at least in the haematological setting. We have demonstrated that the gene expression and DNA methylation profiles of cells taken from the spleens of engrafted mice are highly correlated to the original primary tumour. Given the similarity to the primary tumour, our study confirms the opportunity to investigate gene expression and DNA methylation biomarkers in response to novel treatment strategies.

\section{Availability of supporting data}

The data sets supporting the results of this article are included within the article and its additional files. All microarray data presented in this paper have been deposited into 
Gene Expression Omnibus (http://www.ncbi.nlm.nih.gov/ geo/) with the identifiers GSE57581 and GSE57491.

\section{Additional files}

\section{Additional file 1: Table S1. SEQUENOM EpiTYPER primers used in this study.}

Additional file 2: Table S2. Differentially methylated probes between primary and xenograft tumours.

Additional file 3: Figure S1. Heatmap plot of the most significant DNA methylation (A) and gene expression (B) probes differentiating primary to xenograft tumours. While the samples clustered accordingly, the magnitude of DNA methylation and gene expression differences across these probes were minimal.

Additional file 4: Table S3. Differentially expressed probes between primary and xenograft tumours.

Additional file 5: Table S4. DAVID ontology list of functional pathways of genes found to be associated with prednisolone response.

Additional file 6: Figure S2. SEQUENOM Validation of 17 probes identified as significantly differentially methylated between primary and xenograft tumours. The green side column depicts PGR samples, while red depicts PPR samples. DNA methylation of these probes were able to separate tumours on prednisolone response, with 4 (depicted in

Figure 4) giving the most discriminatory power.

\section{Competing interests}

The authors declare no actual or perceived competing interests.

\section{Authors' contributions}

$N C W, V A B, J M C, R S$ and RBL designed the study; NCW, VAB and JM performed the experiments; NCW, VAB, JM, MP-B and JN analysed data; $N C W, V A B, R S$ and RBL interpreted the data and wrote the manuscript. All authors read and approved the final manuscript.

\section{Acknowledgements}

This work was supported by an NHMRC Project Grant to JC, RS and RBL, and an NHMRC Research Fellowship to RBL. NW has been supported by the Leukaemia Foundation of Australia, My Room and the Children's Cancer Centre Foundation. VB was supported by a scholarship from the Leukaemia Foundation of Australia. The Murdoch Childrens Research Institute is supported by the Victorian Operational Infrastructure Grant. We thank Dr Benjamin Ong for assistance with the SEQUENOM Facility. Children's Cancer Institute Australia for Medical Research is affiliated with the University of New South Wales and the Sydney Children's Hospitals Network.

\section{Author details}

${ }^{1}$ Murdoch Childrens Research Institute, Royal Children's Hospital, Flemington Road, Parkville, Victoria 3052, Australia. 'Ludwig Institute for Cancer Research, Olivia Newton John Cancer and Wellness Centre, Austin Hospital, Burgundy Street, Heidelberg, Victoria 3184, Australia. ${ }^{3}$ Children's Cancer Institute Australia for Medical Research, Lowy Cancer Research Centre, UNSW, PO Box 81, Sydney, NSW 2052, Australia. ${ }^{4}$ Department of Paediatrics, The University of Melbourne, Royal Children's Hospital, Flemington Road, Parkville, Victoria 3052, Australia.

Received: 29 November 2013 Accepted: 20 May 2014 Published: 1 June 2014

\section{References}

1. Williams SA, Anderson WC, Santaguida MT, Dylla SJ: Patient-derived xenografts, the cancer stem cell paradigm, and cancer pathobiology in the 21st century. Lab Invest 2013, 93:970-982.

2. Tentler JJ, Tan A-C, Weekes CD, Jimeno A, Leong S, Pitts TM, Arcaroli JJ, Messersmith WA, Eckhardt SG: Patient-derived tumour xenografts as models for oncology drug development. Nat Rev Clin Oncol 2012, 9:338-350.
3. Vandamme T: Use of rodents as models of human diseases. J Pharm Bioallied Sci 2014, 6:2.

4. Bachmann PS, Lock RB: In vivo models of childhood leukemia for preclinical drug testing. Curr Drug Targets 2007, 8:773-783.

5. Anderson K, Lutz C, Van Delft FW, Bateman CM, Guo Y, Colman SM, Kempski H, Moorman AV, Titley I, Swansbury J, Kearney L, Enver T, Greaves $\mathrm{M}$ : Genetic variegation of clonal architecture and propagating cells in leukaemia. Nature 2010, 469:356-361.

6. Carol H, Boehm I, Reynolds CP, Kang MH, Maris JM, Morton CL, Gorlick R, Kolb EA, Keir ST, Wu J, Wozniak AE, Yang Y, Manfredi M, Ecsedy J, Wang J, Neale G, Houghton PJ, Smith MA, Lock RB: Efficacy and pharmacokinetic/ pharmacodynamic evaluation of the Aurora kinase A inhibitor MLN8237 against preclinical models of pediatric cancer. Cancer Chemother Pharmacol 2011, 68:1291-1304.

7. Carol H, Szymanska B, Evans K, Boehm I, Houghton PJ, Smith MA, Lock RB: The anti-CD19 antibody-drug conjugate SAR3419 prevents hematolymphoid relapse postinduction therapy in preclinical models of pediatric acute lymphoblastic leukemia. Clin Cancer Res 2013, 19:1795-1805.

8. Clappier E, Gerby B, Sigaux F, Delord M, Touzri F, Hernandez L, Ballerini P, Baruchel A, Pflumio F, Soulier J: Clonal selection in xenografted human T cell acute lymphoblastic leukemia recapitulates gain of malignancy at relapse. J Exp Med 2011, 208:653-661.

9. Liem NLM, Papa RA, Milross CG, Schmid MA, Tajbakhsh M, Choi S, Ramirez CD, Rice AM, Haber M, Norris MD, MacKenzie KL, Lock RB: Characterization of childhood acute lymphoblastic leukemia xenograft models for the preclinical evaluation of new therapies. Blood 2004, 103:3905-3914.

10. Lock RB, Liem N, Farnsworth ML, Milross CG, Xue C, Tajbakhsh M, Haber M, Norris MD, Marshall GM, Rice AM: The nonobese diabetic/severe combined immunodeficient (NOD/SCID) mouse model of childhood acute lymphoblastic leukemia reveals intrinsic differences in biologic characteristics at diagnosis and relapse. Blood 2002, 99:4100-4108.

11. Maude SL, Tasian SK, Vincent T, Hall JW, Sheen C, Roberts KG, Seif AE, Barrett DM, Chen IM, Collins JR, Mullighan CG, Hunger SP, Harvey RC, Willman CL, Fridman JS, Loh ML, Grupp SA, Teachey DT: Targeting JAK1/2 and $\mathrm{mTOR}$ in murine xenograft models of Ph-like acute lymphoblastic leukemia. Blood 2012, 120:3510-3518.

12. Notta F, Mullighan CG, Wang JCY, Poeppl A, Doulatov S, Phillips LA, Ma J, Minden MD, Downing JR, Dick JE: Evolution of human BCR-ABL1 lymphoblastic leukaemia-initiating cells. Nature 2011, 469:362-367.

13. Kamel-Reid S, Letarte M, Doedens M, Greaves A, Murdoch B, Grunberger T, Lapidot T, Thorner P, Freedman MH, Phillips RA: Bone marrow from children in relapse with pre-B acute lymphoblastic leukemia proliferates and disseminates rapidly in scid mice. Blood 1991, 78:2973-2981.

14. Nijmeijer BA, Mollevanger P, Van Zelderen-Bhola SL, Kluin-Nelemans HC, Willemze R, Falkenburg $\mathrm{JH}$ : Monitoring of engraftment and progression of acute lymphoblastic leukemia in individual NOD/SCID mice. Exp Hematol 2001, 29:322-329.

15. Saferali A, Grundberg E, Berlivet S, Beauchemin H, Morcos L, Polychronakos C, Pastinen T, Graham J, McNeney B, Naumova AK: Cell culture-induced aberrant methylation of the imprinted IG DMR in human lymphoblastoid cell lines. Epigenetics 2010, 5:50-60.

16. Samuels AL, Peeva VK, Papa RA, Firth MJ, Francis RW, Beesley AH, Lock RB, Kees UR: Validation of a mouse xenograft model system for gene expression analysis of human acute lymphoblastic leukaemia. BMC Genomics 2010, 11:256

17. Bhadri VA, Cowley MJ, Kaplan W, Trahair TN, Lock RB: Evaluation of the NOD/SCID xenograft model for glucocorticoid-regulated gene expression in childhood B-cell precursor acute lymphoblastic leukemia. BMC Genomics 2011, 12:565

18. Du P, Kibbe WA, Lin SM: lumi: a pipeline for processing Illumina microarray. Bioinformatics 2008, 24:1547-1548

19. Wettenhall JM, Smyth GK: limmaGUI: A graphical user interface for linear modeling of microarray data. Bioinformatics 2004, 20:3705-3706.

20. Ollikainen $\mathrm{M}$, Smith $\mathrm{KR}$, Joo EJ-H, Ng H-K, Andronikos $\mathrm{R}$, Novakovic $B$, Abdul Aziz NK, Carlin JB, Morley R, Saffery R, Craig JM: DNA methylation analysis of multiple tissues from newborn twins reveals both genetic and intrauterine components to variation in the human neonatal epigenome. Hum Mol Genet 2010, 19:4176-4188.

21. Gutierrez-Arcelus M, Lappalainen T, Montgomery SB, Buil A, Ongen $H$, Yurovsky A, Bryois J, Giger T, Romano L, Planchon A, Falconnet E, Bielser D, Gagnebin M, Padioleau I, Borel C, Letourneau A, Makrythanasis P, Guipponi 
M, Gehrig C, Antonarakis SE, Dermitzakis ET: Passive and active DNA methylation and the interplay with genetic variation in gene regulation. Elife 2013, 2:e00523-e00523.

22. Pai AA, Bell JT, Marioni JC, Pritchard JK, Gilad Y: A Genome-wide study of DNA methylation patterns and gene expression levels in multiple human and chimpanzee tissues. PLoS Genet 2011, 7:e1001316

23. Zhao Y, Rangnekar VM: Apoptosis and tumor resistance conferred by Par-4. Cancer Biol Ther 2008, 7:1867-1874.

24. Nagai MA, Gerhard R, Salaorni S, Fregnani JHTG, Nonogaki S, Netto MM, Soares FA: Down-regulation of the candidate tumor suppressor gene PAR-4 is associated with poor prognosis in breast cancer. Int J Oncol 2010, 37:41-49.

25. Moreno-Bueno G, Fernandez-Marcos PJ, Collado M, Tendero MJ, Rodriguez-Pinilla SM, Garcia-Cao I, Hardisson D, Diaz-Meco MT, Moscat J, Serrano M, Palacios J: Inactivation of the candidate tumor suppressor par-4 in endometrial cancer. Cancer Res 2007, 67:1927-1934.

26. Boehrer S, Chow KU, Puccetti E, Ruthardt M, Godzisard S, Krapohl A, Schneider B, Hoelzer D, Mitrou PS, Rangnekar VM, Weidmann E: Deregulated expression of prostate apoptosis response gene-4 in less differentiated lymphocytes and inverse expressional patterns of par-4 and bcl-2 in acute lymphocytic leukemia. Hematol J 2001, 2:103-107.

27. Fortier JM, Payton JE, Cahan P, Ley TJ, Walter MJ, Graubert TA: POU4F1 is associated with $\mathrm{t}(8 ; 21)$ acute myeloid leukemia and contributes directly to its unique transcriptional signature. Leukemia 2010, 24:950-957.

28. Dunne J, Gascoyne DM, Lister TA, Brady HJM, Heidenreich O, Young BD: AML1/ETO proteins control POU4F1/BRN3A expression and function in $\mathrm{t}(8 ; 21)$ acute myeloid leukemia. Cancer Res 2010, 70:3985-3995.

29. Dunne J, Mannari D, Farzaneh T, Gessner A, Van Delft FW, Heidenreich O, Young BD, Gascoyne DM: AML1/ETO and POU4F1 synergy drives B-lymphoid gene expression typical of $\mathrm{t}(8 ; 21)$ acute myeloid leukemia. Leukemia 2012, 26:1131-1135.

doi:10.1186/1471-2164-15-416

Cite this article as: Wong et al:: Stability of gene expression and epigenetic profiles highlights the utility of patient-derived paediatric acute lymphoblastic leukaemia xenografts for investigating molecular mechanisms of drug resistance. BMC Genomics 2014 15:416.

\section{Submit your next manuscript to BioMed Central and take full advantage of:}

- Convenient online submission

- Thorough peer review

- No space constraints or color figure charges

- Immediate publication on acceptance

- Inclusion in PubMed, CAS, Scopus and Google Scholar

- Research which is freely available for redistribution 